\title{
A 3' Splice Site Mutation in the Thyroglobulin Gene Responsible for Congenital Goiter with Hypothyroidism
}

\author{
Tamio leiri," Pascale Cochaux,, Héctor M. Targovnik," Mitsuo Suzuki," \\ Shin-Ichi Shimoda," Jason Perret," and Gilbert Vassart" \\ *Department of Endocrinology and Internal Medicine, Dokkyo University School of Medicine, Mibu, Tochigi 321-02, Japan; "Institute of \\ Endocrinology, Gunma University, Gunma-Ken 371, Japan; ${ }^{\circledR}$ Catedra de Genetica y Biologia Molecular, Facultad de Farmacia y \\ Bioquimica, Universidad de Buenos Aires, Buenos Aires, Argentina; ' Service de Génétique, Hôpital Erasme, 1070 Brussels, Belgium; \\ and 'Institut de Recherche Interdisciplinaire en Biologie Humaine et Nucléaire, Free University of Brussels, 1070 Brussels, Belgium
}

\begin{abstract}
A case of congenital goiter with defective thyroglobulin synthesis has been studied in molecular terms. The patient is the fifth of a kindred of six, three of which have a goiter. The parents are first cousins. Segregation of thyroglobulin alleles in the family was studied by Southern blotting with a probe revealing a diallelic restriction fragment length polymorphism (RFLP). The results demonstrated that the three affected siblings were homozygous for the RFLP. Northern blotting analysis of the goiter RNA with a thyroglobulin probe suggested that thyroglobulin mRNA size was slightly reduced. Polymerase chain reaction amplification of the $8.5-\mathrm{kb}$ thyroglobulin mRNA as overlapping cDNA fragments demonstrated that a 200-bp segment was missing from the $5^{\prime}$ region of the goiter mRNA. Subcloning and sequencing of the cDNA fragments, and of the patient genomic DNA amplified from this region, revealed that exon 4 is missing from the major thyroglobulin transcript in the goiter, and that this aberrant splicing is due to a $\mathbf{C}$ to $\mathbf{G}$ transversion at position minus 3 in the acceptor splice site of intron 3. The presence in exon 4 of a putative donor tyrosine residue (Tyrosine $\mathrm{n}^{\mathrm{r}}$ 130) involved in thyroid hormone formation provides a coherent explanation to the hypothyroid status of the patient. (J. Clin. Invest. 1991.88:1901-1905.) Key words: polymerase chain reaction • thyroid $\bullet$ hormonogenic tyrosine $\bullet$ consanguinity $\bullet$ splicing
\end{abstract}

\section{Introduction}

While most cases of congenital hypothyroidism are due to agenesis of the thyroid gland, dyshormonogenesis represents an interesting minority of cases with a goiter, where a mutation is suspected in one of the genes encoding the key proteins involved in the biosynthesis of thyroid hormones (1). Amongst these, defects in thyroglobulin synthesis have been documented, in man and in animal models (1-4, and references therein).

T. Ieiri and P. Cochaux contributed equally to the study.

Address correspondence to P. Cochaux, Ph. D., Service de Génétique, Campus Erasme, BAT.C, 808 Route de Lennik, 1070 Brussels, Belgium. 1991

Received for publication 5 June 1991 and in revised form 20 August

J. Clin. Invest.

(C) The American Society for Clinical Investigation, Inc. 0021-9738/91/12/1901/05 $\$ 2.00$

Volume 88, December 1991, 1901-1905
Thyroglobulin is the $660-\mathrm{kD}$ dimeric biosynthetic precursor of thyroid hormones. After iodination of specific tyrosine residues by a thyroperoxidase and hydrogen peroxide dependent mechanism, some of the resulting iodotyrosines couple within the thyroglobulin polypeptide to form the iodothyronines $\mathrm{T} 4$ and $\mathrm{T} 3(5,6$, and references therein). Biochemical analysis of goiter tissue from human or animal cases with defective thyroglobulin production led to their classification into two categories: "quantitative" defects where very little immunoreactive thyroglobulin can be detected and "qualitative" defects where the defect is suspected to reside in the primary structure of a thyroglobulin produced in normal amounts (1). In the bovine, a nonsense mutation in the 9th exon of the thyroglobulin gene has been demonstrated in the hereditary goiter of the South African cattle (7). Up to now, however, the molecular lesion(s) causing congenital goiters with thyroglobulin deficiency remain unknown in man.

In this study, we have identified a $\mathrm{C}$ to $\mathrm{G}$ transversion in the acceptor splice site of intron 3 of the thyroglobulin gene as responsible for hereditary goiter with hypothyroidism in a consanguineous family. The resulting thyroglobulin transcripts lack exon 4 and, consequently, miss codon $n^{r} 130$ which has been proposed to encode an important hormonogenic tyrosine residue ( 8$)$.

\section{Methods}

Patient. The clinical and endocrine status of the patient, together with the biochemical analysis of thyroid proteins, have been described (9). Briefly, the propositus is the fifth of a kindred of six, three of whom have a voluminous goiter (Fig. 1, pedigree). The parents are first cousins. The patient, a 33-yr-old female, was admitted to the hospital because of a large goiter and short stature. She had already undergone thyroidectomy twice at the age of 3 and 15 . The goiter size had gradually increased over the last five years. On admission, she was $132 \mathrm{~cm}$, and weighed $36 \mathrm{~kg}$. A large asymmetrical and multinodular goiter was easily visible and palpable. Apart from the short stature, the physical examination was normal. While the neurological examination was also normal, the intelligence quotient was 86 as evaluated by TanakaBinet's method, and the mental age was that of a 13-yr-old child. The routine biochemical, hematological, and serological examinations were all within the normal range. The thyroid function tests on admission are summarized in Table I. Because of tracheal compression symptoms, the patient received a total thyroidectomy, and was subsequently treated with $\mathrm{T} 4(100 \mu \mathrm{g} / \mathrm{d})$. The weight of the tissue removed at surgery was $\sim 350 \mathrm{~g}(9)$. The thyroidal ${ }^{123}$ I-uptake was $59.8 \%$ before and $54.5 \%$ after perchlorate $\left(\mathrm{KClO}_{4} 400 \mathrm{mg}\right)$ administration. Normal activity of thyroid peroxidase and coupling activity have been reported in this patient (10).

The following commercially available kits were used for hormone assays: thyrotropin-stimulating hormone (TSH), free $T_{4}$, and free $T_{3}$ : 

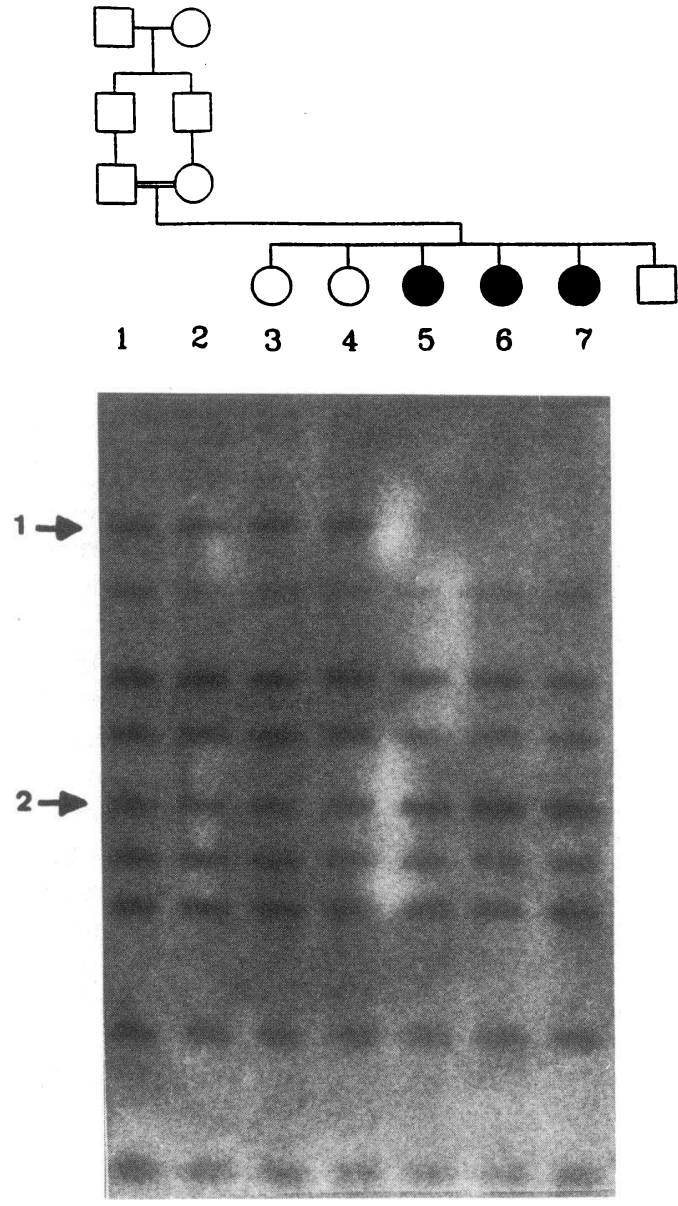

Figure 1. Family structure and thyroglobulin restriction fragment length polymorphism results. $10 \mu \mathrm{g}$ of genomic DNA from the parents (lanes 1 and 2), two healthy children (lanes 3 and 4 ), and three affected children (lanes 5-7), have been hybridized with phTg1 cDNA probe, after restriction with Pvu II and Southern blotting. Arrows indicate the polymorphic fragments. The parents and the healthy children are heterozygous $(1,2)$, and the affected children are homozygous $(2,2)$.

Daiichi Radiochemicals, Tokyo, Japan; $\mathrm{T}_{4}, \mathrm{~T}_{3}$, and thyroxine-binding globulin: Dainabbot Co., Tokyo, Japan; thyroglobulin: Eiken Labs, Tokyo, Japan. Protein-bound iodine was determined by autoanalyzer (Technicon Instruments Corp., Tarrytown, NY).

Table I. Thyroid Function Tests on Admission

\begin{tabular}{lcc}
\hline & Patient's result & Normal range \\
\hline $\mathrm{T} 4 \mu \mathrm{g} / \mathrm{dl}$ & 1.0 & $5.0-13.0$ \\
Free T4 $\mathrm{ng} / \mathrm{dl}$ & 0.2 & $0.8-2.4$ \\
$\mathrm{~T} 3 \mathrm{ng} / \mathrm{ml}$ & 1.8 & $1.0-2.0$ \\
Free T3 $\mathrm{pg} / \mathrm{ml}$ & 7.4 & $2.5-6.0$ \\
$\begin{array}{l}\text { Protein-bound iodine } \mu \mathrm{g} / \mathrm{dl} \\
\text { Thyrotropin-stimulating } \\
\quad \text { hormone } \mu \mathrm{U} / \mathrm{ml}\end{array}$ & 8.7 & $4.0-8.0$ \\
$\begin{array}{l}\text { Thyroxine-binding } \\
\text { globulin } \mu \mathrm{g} / \mathrm{ml}\end{array}$ & 57.0 & $<9$ \\
Thyroglobulin $\mathrm{ng} / \mathrm{ml}$ & 25.0 & $15-30$ \\
& 5.1 & $<30$ \\
\hline
\end{tabular}

Molecular genetics techniques. RNA samples were prepared from goiter tissue frozen in liquid nitrogen at the time of surgery, according to standard procedures (11). DNA was prepared from whole blood sampled on EDTA (11).

Northern and Southern blotting was performed according to standard procedures (11). The probe was a 1,663-bp fragment from human thyroglobulin cDNA (12) labeled to ca $10^{8}$ disintegrations $\mathrm{min}^{-1}$ per $\mu \mathrm{g}$ by random priming (13).

Amplification of selected portions of the thyroglobulin CDNA was performed by reverse polymerase chain reaction (PCR) ${ }^{1}$ as follows: cDNA was synthesized using $1 \mu \mathrm{g}$ of total RNA, 50 pmol of each reverse primers, $200 \mathrm{U}$ of Moloney murine leukemia virus reverse transcriptase (Bethesda Research Laboratories, Gaithersburg, MD), and 20 $\mathrm{U}$ of RNase inhibitor (RNasin; Promega Biotec, Madison, WI), in a standard buffer $(50 \mathrm{mM} \mathrm{KCl}, 2.5 \mathrm{mM} \mathrm{MgCl}, 100 \mu \mathrm{g} / \mathrm{ml} \mathrm{BSA}, 20 \mathrm{mM}$ Tris $\mathrm{HCl} \mathrm{pH8}$, and $1 \mathrm{mM}$ each dNTP, in a total reaction vol of $20 \mu \mathrm{l}$ ) during $1 \mathrm{~h}$ at $42^{\circ} \mathrm{C}$ (after a 10 -min room temperature incubation to allow hybridization of the primers). The reverse transcriptase was inactivated at $95^{\circ} \mathrm{C}$. Amplification by the polymerase chain reaction took place in a $100-\mu 1$ reaction mixture containing the $20-\mu l$ reverse transcription reaction product, $10 \%$ DMSO, $2 \mathrm{U}$ of Thermus aquaticus DNA polymerase (Ampli Taq; Perkin-Elmer Cetus, Norwalk, CT) and a buffer (same as in RT reaction, except for the dNTP which were kept at $200 \mu \mathrm{M}$ in the PCR) with 50 pmol of each forward primer. Amplification was performed during 35 cycles; each cycle included denaturation for $30 \mathrm{~s}$ at $92^{\circ} \mathrm{C}$, primer annealing for $45 \mathrm{~s}$ at $55^{\circ} \mathrm{C}$, and primer extension for $1 \min 30 \mathrm{~s}$ at $72^{\circ} \mathrm{C}$.

Genomic DNA amplification was performed in standard conditions, using $1 \mu \mathrm{g}$ of DNA and $1 \mu \mathrm{g}$ of each primer (forward and reverse).

The product of amplification was analyzed by agarose gel electrophoresis (11), visualized by staining with ethidium bromide and the relevant DNA fragments identified by Southern blotting.

The primers used for PCR amplification of the 5 ' end of thyroglobulin cDNA were 5'GAGATCTTCACCCTGCTGGCCTCC3' (forward, exon 1) + 5'CAGTGAAGGTGGAAGGAAGGTCCA3' (reverse, exon 7) (cDNA 1-800), and 5'TGGACCTTCCTTCCACCTTCACTG3' (forward, exon 7) + 5'CTCCAGGAGAGAAGCAAGGAATTT3' (reverse, exon 9) (cDNA 800-1,700). The primers used to amplify genomic DNA were 5'ATCTAACATTGCTCC3' (forward, intron 3) $+5^{\prime}$ 'CACATCACACTGAAC3' (reverse, exon 4). To allow easy cloning, restriction sites have been incorporated into the PCR fragments by adding specific sequences at the $5^{\prime}$ end of the primers (Hind III site to the forward primers, and Xba I to the reverse primers).

PCR-generated fragments were subcloned in $\mathrm{M} 13 \mathrm{mp} 18$ and $\mathrm{mp} 19$ and sequenced on both strands (370A DNA Sequencer; Applied Biosystems, Inc., Foster City, CA).

\section{Results}

The hormonal status of the patient is illustrated in Table $\mathrm{I}$. Together with the clinical and familial history (see patient description above and pedigree on Fig. 1), this indicated primary hypothyroidism of genetic origin. Analysis of thyroid (iodo)proteins from a surgical sample was compatible with a thyroglobulin defect: little if any iodinated 19s material showing immunoreactivity with anti-human thyroglobulin antibodies, presence in abundance of iodinated albumin-like material (9). As a decrease of thyroglobulin due to rapid turnover is expected in thyroid tissue exposed to hyperstimulation by TSH, irrespective of the nature of the defect, we decided to investigate whether the goitrous phenotype would cosegregate with a particular thyroglobulin gene allele in this consan-

\footnotetext{
1. Abbreviation used in this paper: PCR, polymerase chain reaction.
} 
guineous family. A previously described thyroglobulin restriction fragment length polymorphism detected with Pvu II (14) was selected on the basis that both parents were heterozygous. Fig. 1 demonstrates that all affected children carried the same thyroglobulin alleles, as demonstrated by Southern blotting of DNA extracted from their blood. This was suggestive of a linkage between the mutation and the thyroglobulin gene.

The presence and integrity of thyroglobulin gene transcripts were studied in tissue obtained from the goiter by Northern blotting (Fig. 2). When compared to RNA from a normal gland or from a Hashimoto goiter, no dramatic difference could be observed. All three tissues harbored similar amounts of a partially degraded thyroglobulin mRNA, showing up like a smear with a maximal size of $\sim 8.5 \mathrm{~kb}$, the expected size of intact thyroglobulin message $(15,16)$. Closer inspection of the autoradiograph suggested that mRNA from the congenital goiter could be slightly smaller than the normal or Hashimoto controls. As this would be compatible with the absence from the transcripts of one of the 40 or so small exons of the thyroglobulin gene (17-19), we analyzed in more detail the structure of the goiter mRNA by reverse PCR.

The thyroglobulin cDNA sequence was arbitrarily divided into several overlapping portions which were amplified individually by reverse PCR using seven couples of primers. When analyzed by agarose gel electrophoresis, the resulting amplified fragments from the goiter and control tissue were of the expected sizes, except for the most $5^{\prime}$ segment from the goiter, which lacked completely the normal 820 -bp fragment. It displayed instead two smaller fragments of 620 and $360 \mathrm{bp}$ (Fig. 3 ). The thyroglobulin nature of the amplified material was verified by Southern blotting and hybridization with thyroglobulin cDNA probes (not shown). Cloning and sequencing of the abnormal fragments from the goiter revealed that they corre-

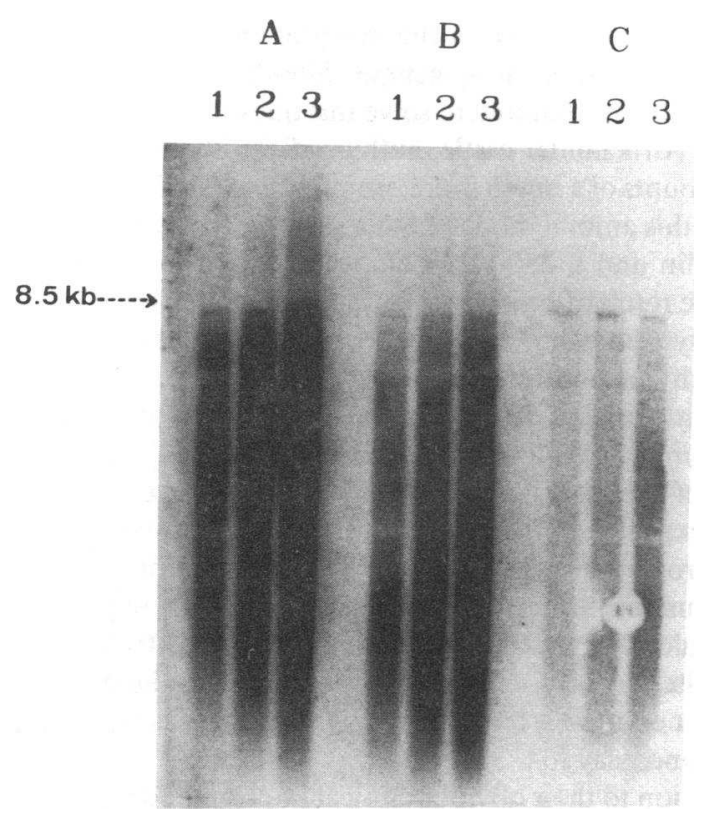

Figure 2. Thyroglobulin mRNA analysis. $5 \mu \mathrm{g}$ (lane 1 ), $10 \mu \mathrm{g}$ (lane 2), or $50 \mu \mathrm{g}$ (lane 3 ) of mRNA extracted from normal thyroid $(A)$, congenital goiter $(B)$, or Hashimoto's goiter $(C)$ tissue, have been hybridized with a thyroglobulin probe. The expected size of thyroglobulin mRNA is $8.5 \mathrm{~kb}$.

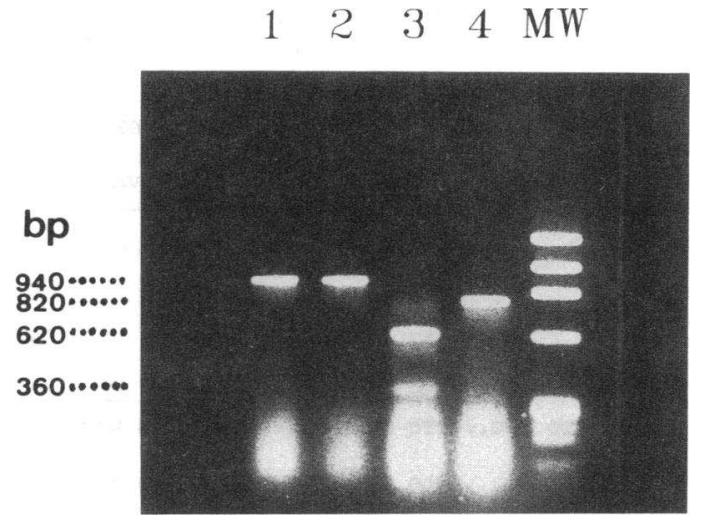

Figure 3. PCR results for the $5^{\prime}$ end of thyroglobulin mRNA. Ethidium bromide visualization of PCR fragments obtained after cDNA amplification with cDNA 1-800 primers (lane 3: goiter; lane 4: normal), or with the cDNA $800-1,700$ primers (lane 1: goiter; lane 2: normal). The molecular weight markers $(M W)$ are Hae III fragments of $\phi \times 174$.

sponded to misspliced transcripts with the 620-bp fragment lacking exon 4, and the 360-bp fragment lacking exons 3, 4, and 5 altogether.

The splice sites bordering exon 4 were PCR-amplified and sequenced from genomic DNA of the goitrous patient and one of her carrier sister. A $C$ to $G$ transversion was observed at position minus 3 in the acceptor site of intron 3 of the patient DNA, as compared to the expected sequence (GAG instead of CAG) (19) and to the sequence of the normal allele of the carrier sister (Fig. 4).

\section{Discussion}

To our knowledge, the case described in this study is the first for which a mutation is found associated with abnormal expression of the thyroglobulin gene in man. As discussed previously, it is likely that congenital goiters with thyroglobulin defects represent a heterogeneous genetic entity (mostly transmitted on the autosomal recessive mode) (1) with a number of different underlying mutations, some patients being probably compound heterozygotes. The interest of the pedigree under study here resided in part in its consanguineous nature, which made it highly probable that the patients would be homozygous for the mutation responsible for the affection.

Mutations affecting the minus 3 position in $3^{\prime}$ splice sites have been found associated with splicing errors in thalassemias (20). Whereas the presence of an AG dinucleotide at the end of introns is truly invariant (21), the nucleotide immediately upstream is preferably a C (72\%), a T (23\%), or an A (4\%) (22). In an extensive compilation of splice sites, $G$ at this position was found in $<1 \%$ of the cases (22). It seems therefore justified to make the mutation found here responsible for the phenotype of the patients in this family.

Abnormally spliced transcripts have not exceptionally been found in normal thyroglobulin mRNA preparations. However, in the reported cases, these represented minor populations coexisting with the major normal message $(7,23,24)$. In the present case, the mutation results in the production in normal amounts of transcripts lacking exon 4. Interestingly, as judged from the reverse PCR (Fig. 3), whereas the major transcripts in 


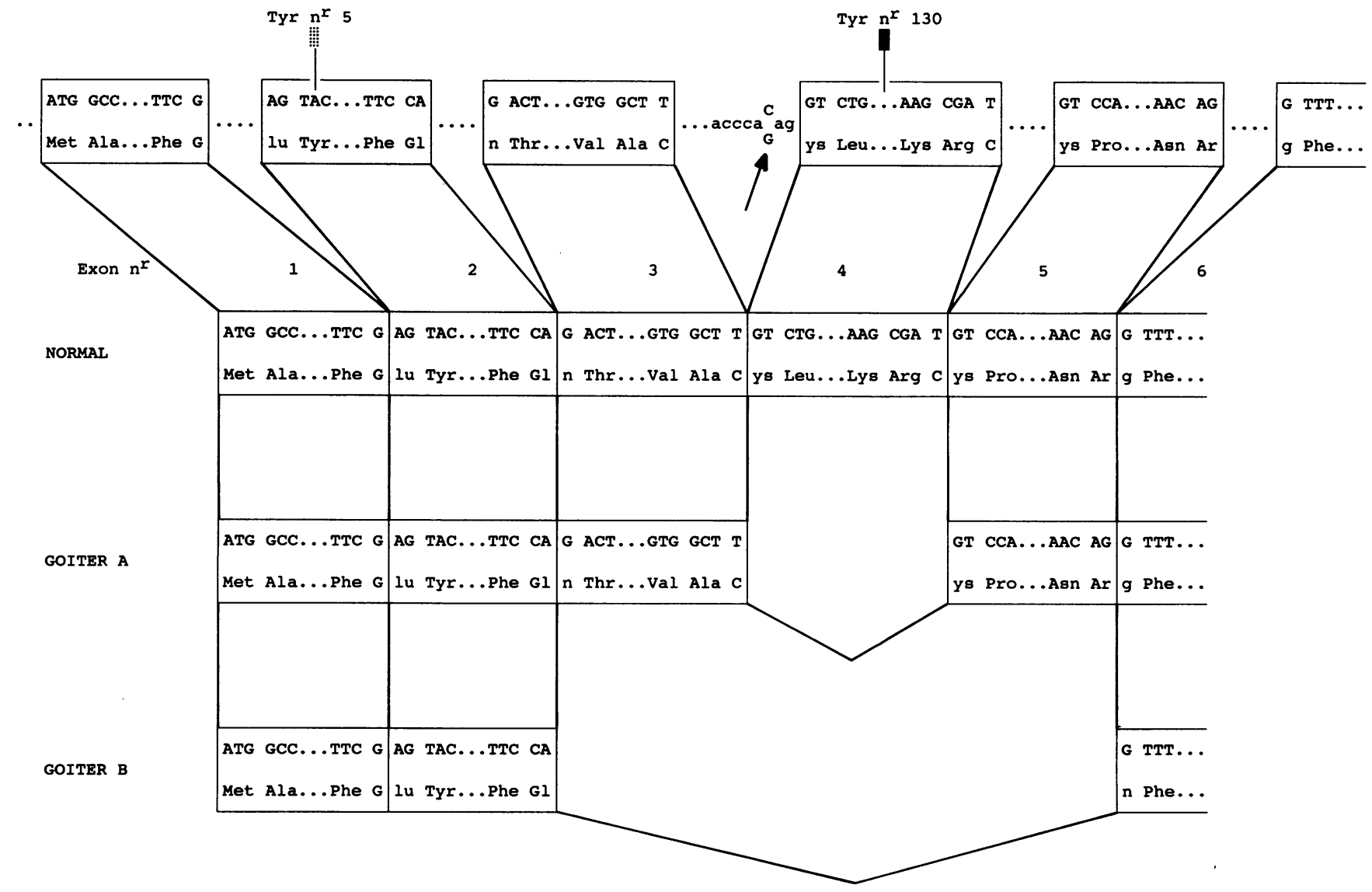

Figure 4. Organization of genomic and cDNA thyroglobulin sequence. Schematical representation of the genomic organization of the $5^{\prime}$ region (6 first exons) of the thyroglobulin gene, together with the normal and goitrous $(A, B)$ cDNA sequences. The arrow points to the mutation $(C-G)$. Tyrosine $\mathrm{n}^{\mathrm{r}} 5$ (the major hormonogenic acceptor residue), and tyrosine $\mathrm{n}^{\mathrm{r}} 130$ (putative donor residue) are highlighted.

the goiter lack neatly only exon 4 , a minor population is devoid of material corresponding to exons 3,4 , and 5 . This suggests that the mutation interferes with the ordered splicing phenomenon in this whole region of thyroglobulin primary transcript.

Removal of exon 4 does not modify the reading frame of thyroglobulin mRNA (19). Together with the fact that normal amounts of the altered message were observed in the goiter, this suggests that the patient thyroid would produce an abnormal thyroglobulin devoid of the corresponding 68 residue peptide segment. This segment is interesting from two viewpoints. First, it encodes a complete copy of the 10 Cys Trp Cys repeat motifs (19) constituting about half of thyroglobulin primary structure $(25,26)$. Although speculative, this suggests that removal of one complete such domain would be compatible with the near to normal folding of the protein; in particular, it would not be expected to interfere with the establishment of correct disulfide bridges in the rest of the molecule. Cystines are known to play an important role in the tertiary structure of thyroglobulin (27). Second, exon 4 encodes tyrosine $n^{r} 130$ which has been proposed by one group as an important donor tyrosine involved in the synthesis of thyroxine, after coupling with the major acceptor tyrosine at position 5 (8). Although identification of donor hormonogenic tyrosines remains a controversial matter (and a series of other residues have been proposed to play this role, refs. 28-31), this provides an appealing explanation for the phenotype of the patients in this family, and may be considered as an argument favoring the role of tyrosine $\mathrm{n}^{\mathrm{r}} 130$ in hormonogenesis. However, there are obviously many other ways in which the absence of the material encoded in exon 4 could interfere with hormonogenesis. Site-directed mutagenesis will probably be required to solve this question. In comparison, in the Afrikaander cattle, euthyroidism is achieved with minute amounts of a much more profoundly altered thyroglobulin (7). In this animal model, both a severely truncated 75-kD thyroglobulin and a $250-\mathrm{kD}$ protein lacking exon 9 are produced as the result of a nonsense mutation at codon $697(7,32)$. However, tyrosines $n^{r} 5$ and $n^{r} 130$ are both present in these abnormal thyroglobulins.

More disturbing is the observation of low levels of immunoreactive thyroglobulin in the patient serum (Table I). Hyperstimulation of the gland by the high circulating levels of TSH would be expected to increase the serum concentration of the altered thyroglobulin (33). Although in contradiction with part of the discussion hereabove, it is conceivable that removal of exon 4 would generate thyroglobulin molecules with a reduced half-life. Alternatively, exon 4 might contribute to the structure of the major epitope(s) recognized by the antibodies used in the radioimmunoassay $(34,35)$.

In addition to their obvious clinical interest for diagnosis of further cases in the same family, the results presented here demonstrate the potential of studying spontaneous mutations as a means to investigate structure-function relationships in thyroglobulin. It is expected that analysis of further mutations by a similar methodology will be gratifying in this respect. 


\section{Acknowledgments}

The continuous support and critical interest of Dr. J. E. Dumont are deeply acknowledged. Thanks are also due to M. Mairie and D. Smet for their excellent technical help.

This work was supported by grants from Ministère de la Politique Scientifique, Fonds pour la Recherche Scientifique et Médicale, Loterie Nationale and ARBD association sans but lucratif, from Monbusho International Scientific Research Program (Joint Research, grant No. 63044027). H. M. Targovnik is an established investigator of the Argentine National Research Council (CONICET) and was a visiting investigator at the Institut de Recherche Interdisciplinaire en Biologie Humaine et Nucléaire, from November 28, 1989 to February 27, 1990, supported by an S\&T grant from Commission of the European Communities.

\section{References}

1. Dumont, J. E., G. Vassart, and S. Refetoff. Thyroid disorders. 1989. In The Metabolic Basis of Inherited Diseases. 6th ed. C. R. Scriver, A. L. Beaudet, W. S. Sly, and D. Valle, editors. McGraw-Hill Inc., NY. 2:1843-1851.

2. Sterk, A., J. E. Van Dijk, G. J. M. Veenboer, A. F. M. Moorman, and J. J. M. De Vijlder. 1989. Normal-sized thyroglobulin mRNA in Dutch goats with thyroglobulin synthesis defect is translated into a 35,000 molecular weight N-terminal fragment. Endocrinology. 124:477-483.

3. Lissitzky, S., J. Bismuth, J. Codaccioni, and G. Cartouzou. 1968. Congenital goiter with iodoalbumin replacing thyroglobulin. J. Clin. Endocrinol. Metab. 28:1797-1803.

4. Taylor, B. A., and L. Rowle. 1987. The congenital goitre mutation is linked to the thyroglobulin gene in the mouse. Proc. Natl. Acad. Sci. USA. 84:19861990.

5. Taurog, A. 1986. In Werner's The Thyroid. S. Ingbar and E. Braverman, editors. Lippincott, Philadelphia. 53-56.

6. Christophe, D., and G. Vassart. 1990. The thyroglobulin gene: evolutionary and regulatory issues. Trends Endocrinol. Metab. 1:351-356.

7. Ricketts, M., M. J. Simons, J. Parma, L. Mercken, Q. Dong, and G. Vassart. 1987. A nonsense mutation causes hereditary goitre in the Afrikander cattle and unmasks alternative splicing of thyroglobulin transcripts. Proc. Natl. Acad. Sci. USA. 84:3181-3184.

8. Marriq, C., P. J. Lejeune, N. Venot, and L. Vinet. 1989. Hormone synthesis in human thyroglobulin: possible cleavage of the polypeptide chain at the tyrosine donor site. FEBS (Fed. Eur. Biochem. Soc.) Lett. 242:414-418.

9. Ieiri, T., T. Emoto, H. Kuroda, O. Tarutani, and S. I. Shimoda. 1987. A case of congenital goitre with impaired thyroglobulin synthesis. In Recent Progress in Thyroidology. Crystal House Press, 106-110.

10. Ohmori, T., T. Ieiri, Y. Asakura, Y. Ohki, T. Teshigori, A. Terasaki, and T. Hosoya. 1991. Application of improved coupling assay method for peroxidase of diseased thyroids: report of three cases. Endocrinol. Jpn. 38:113-117.

11. Sambrook, J., E. F. Fritsch, and T. Maniatis. 1989. Molecular Cloning: A Laboratory Manual. 2nd ed. Cold Spring Harbor Laboratory, Cold Spring Harbor, NY. 1626 pp.

12. Brocas, H., D. Christophe, V. Pohl, and G. Vassart. 1982. Cloning of human thyroglobulin cDNA. FEBS (Fed. Eur. Biochem. Soc.) Lett. 137:189192.

13. Feinberg, A. P., and B. Vogelstein. 1983. A technique for radiolabeling DNA restriction endonuclease fragments to high specific activity. Anal. Biochem. 132:6-13.

14. Simon, P., H. Brocas, C. Rodesch, and G. Vassart. 1985. RFLP detected at the 8q24 locus with a a thyroglobulin cDNA probe. Nucleic Acids Res. 15:373.

15. Vassart, G., L. Verstreken, and C. Dinsart. 1977. Molecular weight of thyroglobulin $33 \mathrm{~S}$ messenger RNA as determined by polyacrylamide gel electro- phoresis in the presence of formamide. FEBS (Fed. Eur. Biochem. Soc.) Lett 79:15-18.

16. Chebath, J., O. Chabaud, J. L. Berge-Lefranc, G. Cartovzou, and S. Lissitzky. 1977. Molecular weight of the thyroglobulin mRNA of sheep thyroid gland. Biochem. Biophys. Res. Commun. 79:267-273.

17. Baas, F., G. J. B. Van Ommen, H. Bikker, A. Arnberg, and J. J. M. De Vijlder. 1986. The human thyroglobulin gene is over $300 \mathrm{~kb}$ long and contains introns up to 64 kb. Nucleic Acids Res. 14:5171-5186.

18. Musti, A. M., E. Avvedimento, V. Polistina, V. M. Ursini, S. Obici, L. Nitsch, S. Cocozza, and R. Di Lauro. 1986. The complete structure of the rat thyroglobulin gene. Proc. Natl. Acad. Sci. USA. 83:323-327.

19. Parma, J., D. Christophe, V. Pohl, and G. Vassart. 1987. Structural organization of the $5^{\prime}$ region of the thyroglobulin gene: evidence for intron loss and exonization during evolution. J. Mol. Biol. 196:769-779.

20. Wong, C., S. E. Antonarakis, S. C. Goff, S. H. Orkin, B. G. Forget, D. G. Nathan, P. J. V. Giardina, and H. H. Kazazian. 1989. $\beta$-Thalassemia due to two novel nucleotide substitutions in consensus acceptor splice sequences of the $\beta$ globin gene. Blood. 73:914-918.

21. Breathnach, R., C. Benoist, K. O'Hare, and F. Gannon. 1978. Ovalbumin gene: evidence for a leader sequence in mRNA and DNA sequences at the exonintron boundaries. Proc. Natl. Acad. Sci. USA. 75:4853-4857.

22. Shapiro, M. B., and P. Senapathy. 1987. RNA splice junctions of different classes of eukaryotes: sequence statistics and functional implications in gene expression. Nucleic Acids Res. 15:7155-7174.

23. Mercken, L., M. Simons, H. J. Brocas, and G. Vassart. 1989. Alternative splicing may be responsible for heterogeneity of thyroglobulin structure. Biochimie (Paris). 71:223-226.

24. Malthiery, Y., C. Marriq, J. L. Berge-Lefranc, J. L. Franc, M. Henry, P. J. Lejeune, P. Ruf, and S. Lissitzky. 1989. Thyroglobulin structure and function: recent advances. Biochimie (Paris). 71:195-210.

25. Mercken, L., M. J. Simons, S. Swillens, M. Massaer, and G. Vassart. 1985. Primary structure of bovine thyroglobulin as deduced from the sequencing of its 8431 Base cDNA. Nature (Lond.). 316:647-651.

26. Malthiéry, Y., and S. Lissitzky. 1987. Primary structure of human thyroglobulin deduced from the sequence of its 8448-base cDNA. Eur. J. Biochem. 165:491-498.

27. De Combrugghe, B., and H. Edelhoch. 1966. The properties of thyroglobulin: the structure of reoxidized thyroglobulin. Biochemistry. 5:2238-2245.

28. Ohmiya, Y., H. Hayashi, T. Kondo, and Y. Kondo. 1990. Location of dehydroalanine residues in the aminoacid sequence of bovine thyroglobulin. Identification of donor tyrosine sites for hormonogenesis in thyroglobulin. $J$. Biol. Chem. 265:9066-9071.

29. Rawitch, A., G. Pollock, and A. Taurog. 1991. Hormone forming sites in human thyroglobulin determined by pulse-chase experiments using ${ }^{125} \mathrm{I}$ and thyroid peroxidase. Proc. of the 10th International Thyroid Conference, The Hague. 365:220. (Abstr.)

30. Lamas, L., P. Anderson, J. Fox, and J. Dunn. 1989. Early iodinated sites in thyroglobulin. J. Biol. Chem. 264:13541-13545.

31. Palumbo, G. 1987. Thyroid hormonogenesis. Identification of a sequence containing iodophenyl donor sites in calf thyroglobulin. J. Biol. Chem. 262:17182-17188.

32. Tassi, V. P. N., R. Di Lauro, P. Van Jaarsveld, and C. G. Alvino. 1984 Two abnormal thyroglobulin-like polypeptides are produced from afrikander cattle congenital goitre. J. Biol. Chem. 259:10507-10510.

33. Van Herle, A., G. Vassart, and J. E. Dumont. 1979. Control of thyroglobulin synthesis and secretion. N. Engl. J. Med. 301:239-249.

34. Dong, Q., M. Ludgate, and G. Vassart. 1989. Towards an antigenic map of human thyroglobulin: identification of ten epitope-bearing sequences within the primary structure of thyroglobulin. J. Endocrinol. 122:169-176.

35. Henry, M., Y. Malthiery, E. Zanelli, and B. Charvet. 1990. Epitope mapping of human thyroglobulin. Heterogenous recognition by thyroid pathologic sera. J. Immunol. 145:3692-3698. 